\title{
Elderly users' level of satisfaction with public transport services in a high-density and transit-oriented city
}

\author{
R.C.P. Wong, W.Y. Szeto, Linchuan Yang, Yuen Chong Li, S.C. Wong \\ The University of Hong Kong
}

\begin{abstract}
Ageing populations are becoming common in many cities, and their rapid growth may lead to serious transportation issues when elderly users' mobility is compromised by their inability to access or use public transport. It is of paramount importance to provide good public transport services to the elderly to maintain their quality of lives. An interviewer-administered face-toface interview survey was conducted in March 2015 in Hong Kong, an example of a highdensity and transit-oriented city, among elderly residents aged 60 and above to evaluate their level of satisfaction with various public transport modes. In this paper, an ordered probit model is calibrated to evaluate the relative importance of the quality of nine service aspects to the overall service performance. An importance-satisfaction analysis is conducted to visualize how best to prioritize actions for improving each of the nine service aspects. The findings reveal that the interviewed elderly individuals considered seat availability as the worst performed service aspect, with which $17.8 \%$ of them were dissatisfied or very dissatisfied. The condition of stations or stops is identified as the most influential factor affecting the overall satisfaction level with public transport services. These two service aspects hold the top priority for enhancement. The drivers' attitude is suggested to be improved additionally if resources allow. For better public transport services to the elderly and thus enhancing their mobility to more actively participate in social activities, appropriate training and guidance to public transport drivers are recommended to enhance their awareness of driving behavior and attitude; provision of seats and shelters is recommended at the bus stops typically frequented by the elderly; and the culture of offering seats to the needy should be promoted through education.
\end{abstract}

Keywords: public transport services, elderly mobility, ordered probit model, importancesatisfaction analysis, transit-oriented city

\section{Introduction}

Ageing populations have become a common global demographic issue. The proportion of the world population aged 60 and over is growing steadily and faster than any other age group. According to a forecast provided by the World Health Organization (2002), there will be 2 billion elderly adults by 2050, constituting an even larger share of society, with about $80 \%$ of them living in developing countries. Likewise, due to sustained low fertility and mortality rates, the population in Hong Kong is ageing at a rapid rate. In 2015, the proportion of people aged 60 and above was the second highest in Asia, exceeded only by that in Japan (United Nations 2015). According to the population projection data for 2015 to 2064, this proportion of Hong Kong residents will reach 38.0\% by 2064 (Census and Statistics Department 2015). Hong Kong's ageing population has created challenges in relation to issues such as health care, old age allowance, senior residence provision, and community transport (Hess 2009; Financial Services and the Treasury Bureau 2013).

Transportation is a basic human need, in that it helps individuals maintain their independence, autonomy, and quality of life (Carp 1988; Dickerson et al. 2007). Due to their deficits in sensory function and musculoskeletal strength, the elderly have become a disadvantaged group that requires special attention. The majority of the elderly, particularly of 
1 those retired and older, are regarded as frequent transit users due to their reliance on public 2 transportation in transit-oriented cities (Szeto et al. 2017), yet their mobility is often 3 compromised by their inability to access or use such transportation. According to Atkins 4 (2001), a lack of mobility deters older people from participating in social activities, which 5 results in low morale, depression and loneliness. Thus, it is important to help the elderly 6 maintain their mobility so that they can continue to engage in civic, social and community 7 life, stay connected to communities and social networks and pursue the human interactions 8 that are so vital to their health and well-being (Dickerson et al. 2007; Julien et al. 2015). The provision of an age-attuned transport system which accommodates the elderly's mobility needs is both urgent and necessary (O’Neill 2016).

In most Western countries, driving is the primary means of transportation, and only a small portion of elderly people use public transport. Various studies (Carp 1988; Atkins 2001; Hildebrand 2003; Banister and Bowling 2004; Newbold et al. 2005; Schmöcker et al. 2008; Buehler and Nobis 2010; Currie and Delbosc 2010; Aceves-González 2015; Voss et al. 2016) with differing degrees of depth and sophistication have focused on the travel patterns of the elderly in an effort to improve their mobility. In contrast with car-dominant cities, transitoriented cities (e.g., Hong Kong, Singapore, and London) have a well-developed and sophisticated transport network, and provide more frequent and relatively reliable public transport services (Land Transport Authority 2012). In Hong Kong, only 14.4\% households own a private car, and about $93.0 \%$ of the labour force uses public transit for their daily commutes (Transport Department 2014). The government tends to improve elderly people's mobility by increasing public transport share, and it has become the major mode of transport with an extremely high transit usage. The transit shares of the elderly aged 60-69, 70-79, 80 and above are 93.6\%, 95.5\%, and 96.5\%, respectively (Szeto et al. 2017). These figures have included the elderly individuals still in the labour force. (The typical retirement age is 60-69 in Hong Kong.) These figures are also comparable to the percentage of the labour force regularly using public transit. However, as the needs and preferences of the elderly are often neglected by transport authorities and policy-makers, the existing public transport policies fail to provide elderly friendly transport facilities such as the provision of priority seats on public transport, more seats at bus stops and train stations, and steady vehicle speeds. Other transport services, such as car-sharing and taxis, is not ideal for the elderly due to difficulties such as finding a driver willing to share a car and high travel costs. As such, it is vital that the aspects of public transport services requiring improvement be identified to better serve the elderly in Hong Kong and enhance their mobility within the community.

Considerable research has been conducted over the years to determine the key factors influencing users' perceptions of public transport, with the goal of establishing new transport policies and identifying the areas that need improvement and image-lifting, based on the levels of importance and satisfaction (Foote and Stuart 1998; Burkhardt et al. 2002; Hensher and Prioni 2002; Tyrinopoulos and Antoniou 2008; dell'Olio et al. 2010; Broome et al. 2013; del Castillo and Benitez 2013; Rojo et al. 2013; Hensher 2014; Shiau and Huang 2014; Das and Pandit 2015; Laverty and Millett 2015; Mouwen 2015). According to the results of the Understanding Senior Transportation Survey (Ritter et al. 2002), the key reasons contributing to the infrequent use of public transport by older Americans, include (1) unreliable public transport services; (2) difficulties in accessing bus stops/stations and transfers; (3) an unavailability of some destinations; and (4) fear of crime. However, the majority of pertinent studies have been focused on car-dominant cities. Limited research has been conducted focusing on the elderly in Hong Kong or other transit-oriented metropolitan cities that provide similar public transport services. In 2011, the Transport Department of Hong Kong conducted an attitudinal Travel Characteristics Survey to reveal elderly users' experiences travelling on public transport (Transport Department 2014). The results of the survey indicated which 
service aspects need improvement, including (1) an insufficient number of priority seats; (2) a rough, uncomfortable ride; and (3) tardy services with long waiting times. The importance and effectiveness of providing these improvements to enhance the overall service performance, however, were not studied. Hence, to identify effective transport policy measures that improve the mobility of elderly public transport users, it is of paramount importance to conduct comprehensive research and gain in-depth insights into the travel preferences of Hong Kong's elderly population.

To address the preceding issues, this study conducts face-to-face interviews with elderly residents in Hong Kong to collect their perceptions on the service quality of public transport modes. An ordered probit model is proposed to determine the importance of the concerned service aspects to the overall service performance. An importance-satisfaction analysis is carried out to identify the priority of service improvement areas. This paper discusses the potential policy implications for improving the mobility of elderly residents.

The contributions of this paper include the following:

- Filling the research gap, adding a reliable empirical study on public transport satisfaction to elderly residents in a high-density and transit-oriented city;

- Identifying the service aspects that influence elderly residents' perceived overall performance of public transport services; and

- Presenting an analytical framework which can be easily applied and efficiently exploited to other cities to determine priorities for action to improve service quality of public transport.

The remainder of this paper proceeds as follows. Section 2 describes the data collection method and the socio-demographic distribution of elderly respondents. Section 3 presents the methodologies of ordered probit model. Section 4 discusses the individual satisfaction level with each service aspect, the results of model calibration, and potential policy implications. Finally, Section 5 concludes the paper and suggests future research directions.

\section{Data}

\subsection{Data collection}

To address the issues discussed in Section 1 of this paper, elderly users' perceptions of public transportation service quality, based on their latest travel experience, were collected during face-to-face interviews. Our interviewers approached the potential respondents, read the questions aloud, and asked about their satisfaction level with public transport services at numerous selected district elderly community centers, clinical centers, public housing estates, parks, and public transport stations throughout Hong Kong in March 2015 during days and nights. It is noteworthy that no special events or incidents occurred during our interview period. In this study, 613 elderly residents aged 60 and above were successfully interviewed from over 3,000 attempts. The response rate was about $16 \%$.

The questionnaire used in the interviews comprised three parts: (1) collection of the respondents' socio-demographic characteristics; (2) identification of the most frequently used public transport mode, including railways, buses, public light buses (which carry a maximum of 16 seated passengers and mainly serve as feeder services) or taxis; and (3) discovery of the respondents' satisfaction levels regarding specific service aspects and overall performance, based on their latest public transport experience.

\subsection{Respondents' socio-demographic characteristics}

Table 1 shows the respondents' socio-demographic characteristics. The sample covered a broad spectrum of public transport users. Adults aged 80 and above were the most numerous, constituting $29.0 \%$ of the total. Gender distribution was quite even, with slightly 
more than half the respondents being male. Regarding the education level, the largest group was formed of users at the primary level, representing more than $60 \%$ of the total, and only $7.5 \%$ of them were educated up to the tertiary level. Over $90 \%$ of the elderly respondents' households did not own any private cars. Over $85 \%$ of the respondents were retired, with only a small proportion engaging in full- or part-time work. For an elderly study, we believe that asking about their monthly expenses would be more meaningful than income. As most of them were retired with no monthly salary from jobs, they most likely spent for their daily expenses from their saving and other assets. They could be rich even they have no monthly income. The monthly personal expenses give us an idea how much they can afford for transportation cost. Close to 70\% of the respondents spent around HKD 1,001 to 5,000 per person each month. Table 1 also provides the distribution of the elderly with different sociodemographic characteristics obtained from some other previous research conducted in Hong Kong for comparison. It is noted that the distribution is similar to that we obtained in this questionnaire survey, which indicates that our sample provides an appropriate representative of Hong Kong's older population.

\section{Table 1}

Respondents' socio-demographic profiles.

\begin{tabular}{|c|c|c|}
\hline Personal Particulars & $\begin{array}{l}\text { Distribution of the elderly } \\
\text { obtained from previous research }\end{array}$ & $\begin{array}{l}\text { Frequency (Percentage) } \\
\text { [Sample Size = 613] }\end{array}$ \\
\hline \multicolumn{3}{|c|}{ 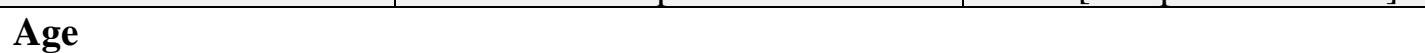 } \\
\hline 60-64 years & $31.8 \%^{\mathrm{a}}$ & $75(12.2 \%)$ \\
\hline 65-69 years & $18.8 \%^{\mathrm{a}}$ & $122(19.9 \%)$ \\
\hline $70-74$ years & $17.1 \%^{\mathrm{a}}$ & $117(19.1 \%)$ \\
\hline 75-79 years & $13.3 \%^{\mathrm{a}}$ & $121(19.7 \%)$ \\
\hline 80 years or above & $19.0 \%^{\mathrm{a}}$ & $178(29.0 \%)$ \\
\hline \multicolumn{3}{|l|}{ Gender } \\
\hline Male & $48.4 \%^{\mathrm{a}}$ & $317(51.7 \%)$ \\
\hline Female & $51.6 \%^{\mathrm{a}}$ & $296(48.3 \%)$ \\
\hline \multicolumn{3}{|l|}{ Education } \\
\hline Primary or below & $69.0 \%{ }^{b}$ & $390(63.6 \%)$ \\
\hline Secondary & $23.0 \%^{b}$ & $177(28.9 \%)$ \\
\hline Tertiary & $8.0 \%^{\mathrm{b}}$ & $46(7.5 \%)$ \\
\hline \multicolumn{3}{|c|}{ Private car available for household use } \\
\hline No & $91.3 \%{ }^{\mathrm{a}}$ & $580(94.6 \%)$ \\
\hline Yes & $8.7 \%^{\mathrm{a}}$ & $33(5.4 \%)$ \\
\hline \multicolumn{3}{|l|}{ Occupation } \\
\hline Full-time job & \multirow{2}{*}{$15.1 \%^{\mathrm{a}}$} & $27(4.4 \%)$ \\
\hline Part-time job & & $19(3.1 \%)$ \\
\hline Homemaker & $12.7 \% \%^{\mathrm{a}}$ & $43(7.0 \%)$ \\
\hline Retired and others & $72.2 \%^{\mathrm{a}}$ & $524(85.5 \%)$ \\
\hline \multicolumn{3}{|c|}{ Monthly personal expenses (HKD) } \\
\hline$\$ 1,000$ or below & \multirow{5}{*}{ Not Available } & $43(7.0 \%)$ \\
\hline$\$ 1,001-\$ 5,000$ & & $422(68.8 \%)$ \\
\hline$\$ 5,001-\$ 10,000$ & & $124(20.2 \%)$ \\
\hline$\$ 10,001-\$ 15,000$ & & $19(3.1 \%)$ \\
\hline$\$ 15,001$ or above & & $5(0.8 \%)$ \\
\hline
\end{tabular}

Note: ${ }^{a}$ The distributions are based on Travel Characteristics Survey 2011 (Transport 
on 2011 Population Census (Census and Statistics Department 2011) for the elderly aged 65 or above.

\subsection{Service aspects contributing to overall service performance}

In this study, we asked the respondents about their level of satisfaction with individual service aspects based on their latest public transport travel experience. To address the characteristics and circumstances of travel in Hong Kong, the selected service aspects reflected the third Transport Characteristics Study (Transport Department 2014). Minor adjustments were made based on two pilot surveys conducted in December 2014 and January 2015. Nine service aspects were thus considered. The questions we asked in the questionnaire for the satisfaction level with each service aspect are shown in Figure 1:

According to your latest travel experience of taking public transport, please rate your satisfaction with each of the service aspects, where 1 represents very dissatisfied, 3 represents neutral, and 5 represents very satisfied.

Service aspects

(1) Seat availability

(Sufficient priority seats?)

[Please ignore this aspect if you traveled by public light bus/taxi]

(2) Travel stability

(Rough and uncomfortable ride, or traveling too fast?)

(3) Wait time for service

(Tardy services or long wait times?)

(4) Driver's attitude

(Vehicle starting to move before passengers are seated?)

[Please ignore this aspect if you traveled by railway]

(5) Ease of boarding and alighting

(High floor platform?)

(6) Internal temperature

(Erratic air-conditioning?)

(7) Walking distance to stations or stops

(Stations or stops are too far apart?)

(8) Travel time and reliability

(Tardy services or long travel times?)

(9) The condition of stations or stops

(Provision of seats and shelters at stations or stops?)

\section{Overall service quality of this transport mode}

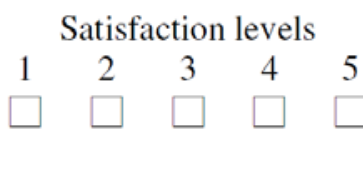

Fig. 1. Questions for the satisfaction level with public transport service quality.

Satisfaction levels were measured on a 5-point Likert scale ranging from 1 (very dissatisfied) to 5 (very satisfied) for all of the individual service aspects. At the end, the respondents were also invited to provide a score for the overall service performance, which was expected to be based on the respondents' satisfaction with the individual service aspects (Olawole and Aloba 2014). It is worth mentioning that we did not ask the public light bus/taxi users to rate their satisfaction with seat availability. As seats are guaranteed in these two transport modes, we assumed they were very satisfied with this service aspect. Likewise, we did not ask the respondents who traveled by railway to rate their satisfaction with driver's attitude. As they did not have any direct interaction with the operator, we assumed that they 
should have neither positive nor negative perception of driver's attitude, and the score on this service aspect was 3 (neutral).

\section{Methodology}

\subsection{Ordered probit model}

The respondents' overall satisfaction levels with public transport services were presented using an ordinal scale. Ordinal scales have a few distinctive features: clearly ordered levels, unknown and unobservable absolute distances between levels and the potential for unequal distances between adjacent ratings (e.g., the distance between ratings 2 and 1 may not be the same as that between ratings 3 and 2 or 5 and 4). It was considered inappropriate to use the ordinary least squares regression model, which would produce biased results (dell’Olio et al. 2010; Iseki and Taylor 2010; Hensher 1990; Zheng et al. 2014).

In this study, an ordered probit model was proposed to relate the overall satisfaction level to the performance of individual service aspects. This model has been widely used to fit the data structure of an ordinal response (Redmond and Mokhtarian 2001; Pai and Saleh 2007; Hasegawa 2010; Su and Bell 2009, 2012). Assuming that $y_{i}$ represents the reported overall satisfaction level of respondent $i$, then a latent (unobserved) variable $y_{i}^{*}$ is introduced as

$$
y_{i}^{*}=\sum_{k} \beta^{k} X_{i}^{k}
$$

where $k$ is the index of the individual service aspect, $X_{i}^{k}$ is the score of the service aspect $k$ as reported by respondent $i$ and $\beta^{k}$ is the corresponding coefficient. $y_{i}$ is equal to $j=1, \ldots, J$ under the following conditions:

$$
y_{i}= \begin{cases}1 & , \text { if } y_{i}^{*} \leq \mu_{1} ; \\ j & , \text { if } \mu_{j-1}<y_{i}^{*} \leq \mu_{j} ; \\ J & , \text { if } y_{i}^{*}>\mu_{J-1},\end{cases}
$$

where $J$ is the number of satisfaction levels (in this case, $J=5$ ) and $\mu_{j}$ is the threshold value (cut-off point) to be estimated for each pair of adjacent levels, where $\mu_{1}<\ldots<\mu_{J-1}$. From Equation (2), the probabilities of $y_{i}$ taking on each of the values of $j=1, \ldots, J$ are determined as

$$
\begin{aligned}
& P\left(y_{i}=1\right)=\Phi\left(\mu_{1}-y_{i}^{*}\right) ; \\
& P\left(y_{i}=j\right)=\Phi\left(\mu_{j}-y_{i}^{*}\right)-\Phi\left(\mu_{j-1}-y_{i}^{*}\right) ; \\
& P\left(y_{i}=J\right)=1-\Phi\left(\mu_{J-1}-y_{i}^{*}\right),
\end{aligned}
$$

where $P\left(y_{i}=j\right)$ is the probability that response variable $y_{i}$ of individual $i$ will take a specific level $j$. $\Phi\left(\mu_{1}-y_{i}^{*}\right)$ is the cumulative standard normal distribution function of $\mu_{1}-y_{i}^{*}$. Both $\beta^{k}$ and $\mu_{j}$ are unknown parameters to be calibrated jointly based on the maximum likelihood estimation method.

\subsection{Importance-satisfaction analysis}

An importance-satisfaction analysis was then conducted to provide a quick visual representation of the service satisfaction scores (collected from the questionnaire survey) and the importance scores (calibrated by the ordered probit model) to identify the priorities for actions to improve the public transport service quality. Accordingly, public transport operators and policy makers can establish action plans that better address the target 
customers' needs, and direct investments toward the most effective enhancement. The concept of the performance evaluation matrix adopted in this study was first introduced by Lambert and Sharma (1990) and has been extensively used in other research on service quality evaluation (Hung et al. 2003; Chen et al. 2007; Wong et al. 2017). There are nine cells in the performance evaluation matrix when the axes are divided into three sections. The service aspects fall into the three cells in the top-left corner are those most in need of improvement, due to their relatively high importance combined with low satisfaction. In contrast, the service aspects in the three cells at the bottom-right corner indicating their relatively low importance and high satisfaction. The subsequent recommendations are to keep monitoring the quality and that no improvement is needed immediately. The service aspects fall in the remaining centered-diagonal cells, reflecting average scores on both satisfaction and importance. These service aspects should be maintained to prevent deterioration.

\section{Results and discussion}

\subsection{Usage of public transport modes and perceived scores for each service aspect}

Table 2 presents the frequency and percentage of respondents who traveled by four popular public transport modes. When asked which mode they used most frequently, up to $90 \%$ of the respondents replied either railways $(40.9 \%)$ or buses $(53.2 \%)$, with only a limited proportion using public light buses (3.4\%) or taxis (2.4\%). The findings are consistent with Szeto et al. (2017) that railways and buses are the most popular public transport modes for the elderly residents in Hong Kong. Given that the mass transit system in Hong Kong provides elderly users with reliable, convenient and cheap services (supported by the public transport HKD 2 fare concession scheme), the elderly have become more willing to travel by railway and bus. Moreover, the respondents noted that the rough, uncomfortable rides provided by public light buses, and the high travel cost of using taxis were their reasons for not using these modes, even though seats are guaranteed and walking distances are usually shorter.

The frequencies and percentages of the public transport modes used in the respondents' latest travel experiences are shown in Table 2. The numbers of each transport mode are close to those of the most frequently used, as discussed above.

Table 2

Frequencies and percentages of respondents' travel experiences by each public transport mode.

\begin{tabular}{|l|c}
\hline Public Transport Modes & $\begin{array}{c}\text { Frequency (Percentage) } \\
\text { [Sample Size }=613 \text { ] }\end{array}$ \\
\hline
\end{tabular}

Most Frequently Used

\begin{tabular}{|l|c|}
\hline Railways & $251(40.9 \%)$ \\
\hline Buses & $326(53.2 \%)$ \\
\hline Public Light Buses & $21(3.4 \%)$ \\
\hline Taxis & $15(2.4 \%)$ \\
\hline
\end{tabular}

Used in the Latest Travel Experience

\begin{tabular}{|l|c|}
\hline Railways & $270(44.0 \%)$ \\
\hline Buses & $299(48.8 \%)$ \\
\hline Public Light Buses & $33(5.4 \%)$ \\
\hline Taxis & $11(1.8 \%)$ \\
\hline
\end{tabular}

Table 3 tabulates the averages and standard deviations of individual aspect scores and the overall service performance of each transport mode used by the respondents in their latest travel experience. The average score for overall service performance was 3.79 (close to 4, representing the score of satisfied), indicating that the respondents were generally satisfied with the current public transport service quality. The mean scores of all of the individual 
1 service aspects were also higher than 3. Travel time and reliability received the highest

2 satisfaction score of 3.72 while seat availability scored the lowest (3.34).

4 Table 3

5 Averages and standard deviations of service aspect scores.

\begin{tabular}{|l|c|}
\hline Service Aspects & $\begin{array}{c}\text { Average (Standard Deviation) } \\
\text { [Sample Size }=613 \text { ] }\end{array}$ \\
\hline Seat availability & $3.34(0.93)$ \\
\hline Travel stability & $3.58(0.76)$ \\
\hline Wait time for service & $3.50(0.92)$ \\
\hline Driver's attitude & $3.39(0.66)$ \\
\hline Ease of boarding and alighting & $3.64(0.85)$ \\
\hline Internal temperature & $3.50(0.81)$ \\
\hline Walking distance to stations or stops & $3.67(0.90)$ \\
\hline Travel time and reliability & $3.72(0.73)$ \\
\hline The condition of stations or stops & $3.48(0.87)$ \\
\hline Overall performance & $3.79(0.71)$ \\
\hline
\end{tabular}

\subsection{Results of model calibration}

The data analysis and statistical software STATA was adopted, using the maximum likelihood estimation method to calculate the coefficient associated with each service aspect, along with the threshold values (cut-off points) between each pair of adjacent levels. As the rating scale representing the degree of satisfaction has five levels, there are four threshold values separating the choices. The estimated coefficient associated with each aspect should be non-negative in theory because individual service quality should have positive or no repercussions on the overall service performance. Furthermore, because each of the variables has the same potential range (i.e., from 1 [very dissatisfied] to 5 [very satisfied]), all of the coefficients are unit-less and can be directly compared.

\section{Table 4}

Coefficients and their t-statistics for the order probit model for satisfaction with public transport service performance.

\begin{tabular}{|l|c|c|}
\hline Explanatory Variables & Coefficients & t-statistics \\
\hline Seat availability & $0.16^{\mathrm{a}}$ & 2.90 \\
\hline Travel stability & $0.28^{\mathrm{a}}$ & 3.87 \\
\hline Wait time for service & $0.14^{\mathrm{b}}$ & 2.38 \\
\hline Driver's attitude & $0.35^{\mathrm{a}}$ & 4.52 \\
\hline Ease of boarding and alighting & $0.18^{\mathrm{a}}$ & 2.94 \\
\hline Internal temperature & 0.08 & 1.23 \\
\hline Walking distance to stations or stops & 0.06 & 1.08 \\
\hline Travel time and reliability & $0.19^{\mathrm{a}}$ & 2.59 \\
\hline The condition of stations or stops & $0.45^{\mathrm{a}}$ & 7.02 \\
\hline$\mu_{1}$ (cut-off point of levels 1 and 2) & $3.41^{\mathrm{a}}$ & 7.52 \\
\hline$\mu_{2}$ (cut-off point of levels 2 and 3) & $4.13^{\mathrm{a}}$ & 9.49 \\
\hline$\mu_{3}$ (cut-off point of levels 3 and 4) & $6.04^{\mathrm{a}}$ & 13.13 \\
\hline$\mu_{4}$ (cut-off point of levels 4 and 5) & $8.24^{\mathrm{a}}$ & 16.35 \\
\hline
\end{tabular}

Note: ${ }^{\mathrm{a}}$ Parameters are significant at the $1 \%$ level; and ${ }^{\mathrm{b}}$ Parameters are significant at the $5 \%$ level. 
Table 4 summarizes the results of the ordered probit model. Seven out of nine of the service aspects are significant at the $5 \%$ level, with the exceptions of walking distance to stations or stops and internal temperature. All four threshold values are significant at the $1 \%$ level, and all of the estimated coefficients are positive. The condition of stations or stops poses the largest coefficient (0.45), followed by those associated with driver's attitude $(0.35)$ and travel stability $(0.28)$. The cut-off points define a range of each satisfaction level. For example, if the calculated $y_{i}^{*}$ is less than $\mu_{1}$ (3.41), the predicted overall satisfaction score is 1 (very dissatisfied). If the calculated $y_{i}^{*}$ is between $\mu_{1}$ and $\mu_{2}$ (3.41 and 4.13), the predicted overall satisfaction score is 2 (dissatisfied). We notice that the range of dissatisfied (0.72) is obviously smaller than that of neutral (1.91) and satisfied (2.20). The findings suggest that most of the elderly would still be satisfied with the public transport service quality with some variations from current condition. Once the predicted overall satisfaction score drops below this range and becomes lower, the thresholds from satisfied to dissatisfied will be reached more and more quickly. This asymmetric perception reflects the difficulty to further improve the public transport service quality and uplift the current satisfaction level from satisfied to very satisfied. In contrast, it would be relatively easier to descend the level from satisfied to neutral, and from neutral to dissatisfied.

\subsection{Priorities for service quality improvement}

Figure 2 shows the service satisfaction score and the importance score of each service aspect, to identify the priorities for actions to improve the public transport service quality. The performance evaluation matrix consists of nine cells with each axis divided into three sections. The two vertical lines (3.386 and 3.656) are determined based on the mean value of the service performance rating of 3.521, plus or minus one standard deviation of 0.135 . Similarly, the two horizontal lines $(0.135$ and 0.365$)$ are calculated by adding or subtracting one standard deviation of 0.115 from the average important rating of 0.250 . The service aspects (in the purple cells) requiring immediate attention and hold the top priority for enhancement are seat availability and the condition of stations or stops. Only travel time and reliability (in the green cells) is categorized as the lowest priority for improvement and is recommended to keep monitoring its service quality. The remaining four service aspects (in the white cells), including seat availability, travel stability, wait time for service, and ease of boarding and aligning, are recommended to be maintained their service quality to prevent deterioration. 


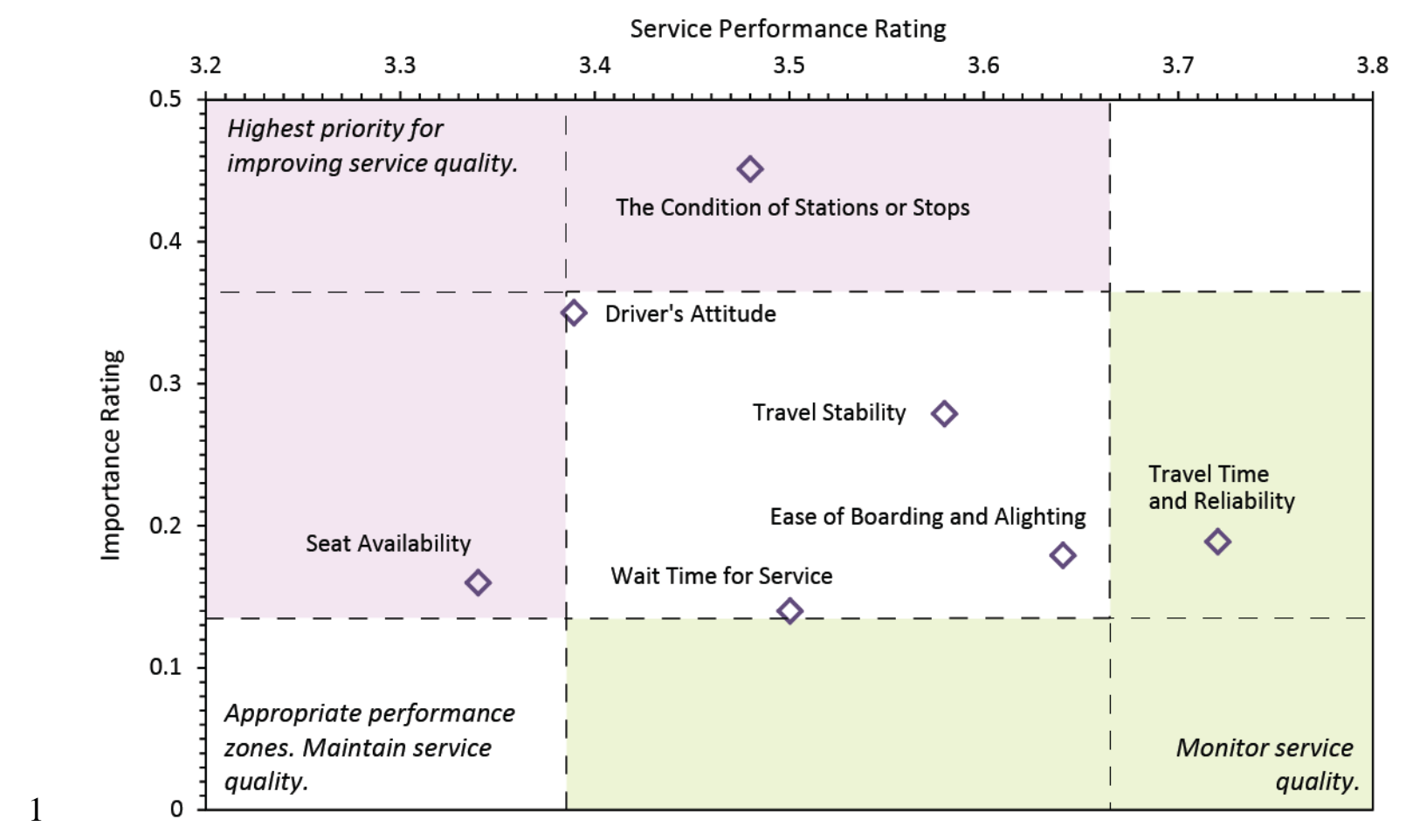

2 Fig. 2. Importance-satisfaction analysis and recommended priorities for service quality 3 improvements.

4

\subsection{Policy implications}

According to the findings of the importance-satisfaction analysis, seat availability holds the top priority for improvement. As seats are guaranteed in public light buses and taxis, the suggested improvement will be applied to railways and buses only. A large proportion of the interviewees (consists of $17.8 \%$ ) considered seat availability either dissatisfied or very dissatisfied. Improving on this aspect could enable the elderly to use transit in a comfortable and safe way greatly, and enhance elderly mobility effectively. Indeed, the provision of priority seats is one of the transport measures undertaken to improve seat availability for the elderly. In Hong Kong, priority seats for people with special needs were first introduced in 2009. Nonetheless, the elderly often have to stand because priority seats are occupied by other passengers. Many passengers have little awareness of offering seats to the elderly around them. A recent study revealed that using mobile phones or tablets is the main reason that passengers neglect to offer seats to the needy on public transport (Department of Applied Social Sciences 2015). Thus, the concern about insufficient priority seats cannot simply be addressed by providing more priority seats. Making it mandatory for users to offer seats to their counterparts with special needs through legislation would be difficult and impractical. To improve the current situation with seat availability, promoting the culture of offering seats to the needy through education should be considered instead. For example, a priority seat campaign could be launched by the government or mass transit operators. Furthermore, the policy-makers may also consider the introduction of a Priority Seat card or badge, as has been a custom in London since 2012, to provide a clear indicator that encourages other passengers to give up their priority seats for the needy.

The condition of stations or stops (provision of seats and shelters) is another service aspect that needs to improve, as it is the most influential factor affecting the overall service performance, as discussed in Section 4.2. Due to the limited road space in congested urban areas, such as narrow footways or inadequate headroom clearance, shelters and seats are not 
1 normally provided at franchised bus stops, public light bus stops, and taxi stands in Hong 2 Kong. Elderly residents may have to wait for services under direct sunlight and rain. Although 3 it may not be feasible to provide sufficient shelters and seats at all bus stops and public light 4 bus stops, policy-makers may consider providing these facilities at locations typically 5 frequented by the elderly, such as outside hospitals, district elderly community centers, social 6 centers, and non-subverted service centers for the elderly. In addition, the real-time time7 estimating system for the arrival of the next service could be extensively introduced at stations 8 and stops to provide passengers with dynamic arrival information, allowing the elderly to alter their public transport mode choice to minimize the waiting time at stations.

In addition, we note that drivers' attitude is a marginal case which is located very close to the cells with the top priority for improvement. We suggest this service aspect being improved if resources allow. As explained in Section 2.3, this service aspect was not applicable for railways, with no direct interaction between passengers and operators. This study, in particular, indicates the poor services provided by buses, public light buses, and taxis. The suggested improvement will enhance the travel experience of about $60 \%$ of the elderly individuals who frequently used these three modes of transport. During the face-toface discussion with the elderly, they complained that drivers were sometimes in haste, and did not pay special attention to the elderly passengers. One example is that vehicles started moving before they were seated. Another example is that door was closed quickly, leading to insufficient time for their boarding and alighting. The road-based public transport operators should, therefore, provide appropriate training and guidance to their drivers in order to enhance their awareness of driving behavior and attitude, and timely evaluate the performance of the drivers.

\section{Conclusion}

The rapid growth of the region's elderly population is predicted to lead to serious mobility problems, as their mobility is often compromised by the inability to access or use public transport. Hence, it is of paramount importance to maintain the quality of elderly people's daily lives by improving and enhancing the level of public transport service. In this study, 613 questionnaire surveys were conducted among elderly respondents aged 60 and above to evaluate their satisfaction level with the current public transport services in Hong Kong, a high-density and transit-oriented city. An ordered probit model was calibrated to evaluate the relative importance of the level of service in relation to nine identified variables. An importance-satisfaction analysis was used to visualize the priorities for action to improve service quality.

According to the results of the ordered probit model, seven service aspects were found to significantly influence the respondents' perceived overall service performance. According to the importance-satisfaction analysis, the service areas in most urgent need of improvement include seat availability and the condition of stations or stops, based on their high importance ratings combined with low satisfaction scores. Furthermore, the drivers' attitude is recommended to be improved if resources allow. It is anticipated that the results will strengthen the capabilities of public transport planners in planning better transport systems and enhancing policy makers' ability to establish new policies that further improve elderly mobility, in particular in transit-oriented cities.

We attempted to include socio-demographic factors (e.g., gender and age) into the model and attempted to calibrate a separate model for each public transport mode. However, probably due to insufficient sample size, the additional socio-demographic factors and the mode specific parameters are not significant and cannot provide us some more policy insights. Therefore, we suggest the following research directions for future study when more samples are available: (1) incorporating socio-demographic factors into the ordered probit model to 
1 verify whether personal particulars alter people's use and perceptions of transit; and (2) calibrating mode-specific models.

\section{Acknowledgements}

This research was supported by a grant from the Central Policy Unit of the Hong Kong Special Administrative Region Government, Public Policy Research Funding Scheme (Project No.: 2014.A8.025.15B). The authors wish to thank Tommy Pui Hang LAM, a student of the Civil Engineering Department, The University of Hong Kong, for his assistance with the data collection and analysis. The authors are grateful to the two reviewers for their constructive comments.

\section{References}

Aceves-González, C., Cook, S., May, A., 2015. Bus use in a developing world city: Implications for the health and well-being of older passengers. Journal of Transport \& Health 2(2), 308-316.

Atkins, W., 2001. Older People: Their Transport Needs and Requirements. Department of the Environment, Transport and the Regions, London, Great Britain.

Banister, D., Bowling, A., 2004. Quality of life for the elderly: The transport dimension. Transport Policy 11(2), 105-115.

Ben-Akiva, M. E., Lerman, S. R. 1985. Discrete choice analysis: Theory and application to travel demand (Vol. 9). MIT press.

Broome, K., Worrall, L., Fleming, J., Boldy, D., 2013. Evaluation of age-friendly guidelines for public buses. Transportation Research Part A: Policy and Practice 53, 68-80.

Buehler, R., Nobis, C., 2010. Travel behavior in aging societies: Comparison of Germany and the United States. Transportation Research Record: Journal of the Transportation Research Board 2182, 62-70.

Burkhardt, J., McGravock, A., Nelson, C., 2002. Improving Public Transit Options for Older Persons. Technical Report Transit Cooperative Research Program Report No. 82, Transportation Research Board, Washington, D.C., United States.

Carp, F.M., 1988. Significance of mobility for the well-being of the elderly. Transportation in An Aging Society: Improving Mobility and Safety of Older Persons, 2, Washington, D.C., National Academy Press.

Census and Statistics Department, Hong Kong, 2011. 2011 Population Census - Thematic Report: Older Persons.

Census and Statistics Department, Hong Kong, 2015. Hong Kong Population Projections 2015-2064.

Chen, S.H., Yang, C.C., Lin, W.T., Yeh, T.M., 2007. Service quality attributes determine improvement priority. The TQM Magazine 19(2), 162-175.

Currie, G., Delbosc, A., 2010. Exploring public transport usage trends in an ageing population. Transportation 37(1), 151-164.

Das, S., Pandit, D., 2015. Determination of level-of-service scale values for quantitative bus transit service attributes based on user perception. Transportmetrica A: Transport Science 11(1), 1-21.

de Dios Ortuzar, J., Willumsen, L.G., 2011. Modelling Transport, 4th Edition. New York: John Wiley \& Sons.

del Castillo, J.M., Benitez, F.G., 2013. Determining a public transport satisfaction index from user surveys. Transportmetrica A: Transport Science 9(8), 713-741. 
dell’Olio, L., Ibeas, A., Cecín, P., 2010. Modelling user perception of bus transit quality. Transport Policy 17(6), 388-397.

Department of Applied Social Sciences, The Hong Kong Polytechnic University, 2015. Offering seats habits reviewed from a public opinion workshop. www.apssweb.polyu.edu.hk/news/Offering\%20seats\%20habits\%20revealed\%20from \%20a\%20public\%20opinion\%20workshop.

Dickerson, A.E., Molnar, L.J., Eby, D.W., Adler, G., Bedard, M., Berg-Weger, M., Classen, S., Foley, D., Horowitz, A., Kerschner, H., 2007. Transportation and aging: A research agenda for advancing safe mobility. The Gerontologist 47(5), 578-590.

Financial Services and the Treasury Bureau, Hong Kong. The 2013-14 Budget. www.budget.gov.hk/2013/eng/budget27.html.

Foote, P., Stuart, D., 1998. Customer satisfaction contrasts: Express versus local bus service in Chicago's North Corridor. Transportation Research Record: Journal of the Transportation Research Board 1618, 143-152.

Gunn, H., Bates, J., 1982. Statistical aspects of travel demand modelling. Transportation Research Part A: General 16(5), 371-382.

Hasegawa, H., 2010. Analyzing tourists' satisfaction: A multivariate ordered probit approach. Tourism Management 31(1), 86-97.

Hensher, D.A., 1990. Hierarchical stated response designs: An application to bus user preferences. Logistics and Transportation Review 26(4), 299-321.

Hensher, D.A., 2014. The relationship between bus contract costs, user perceived service quality and performance assessment. International Journal of Sustainable Transportation 8(1), 5-27.

Hensher, D.A., Prioni, P., 2002. A service quality index for area-wide contract performance assessment. Journal of Transport Economics and Policy 36(1), 93-113.

Hess, D.B., 2009. Access to public transit and its influence on ridership for older adults in two US cities. Journal of Transport and Land Use 2(1), 3-27.

Hildebrand, E.D., 2003. Dimensions in elderly travel behaviour: A simplified activity-based model using lifestyle clusters. Transportation 30(3), 285-306.

Hung, Y.H., Huang, M.L., Chen, K.S., 2003. Service quality evaluation by service quality performance matrix. Total Quality Management 14(1), 79-89.

Iseki, H., Taylor, B.D., 2010. Style versus service? An analysis of user perceptions of transit stops and stations. Journal of Public Transport 13(3), 23-48.

Julien, D., Richard, L., Gauvin, L., Fournier, M., Kestens, Y., Shatenstein, B., Daniel, M., Mercille, G., Payette, H., 2015. Transit use and walking as potential mediators of the association between accessibility to services and amenities and social participation among urban-dwelling older adults: Insights from the VoisiNuAge study. Journal of Transport \& Health 2(1), 35-43.

Lambert, D.M., Sharma, A., 1990. A customer-based competitive analysis for logistics decisions. International Journal of Physical Distribution and Logistics Management, 20(1), 17-24.

Land Transport Authority, Singapore, 2012. Key Transport Statistics of World Cities.

Laverty, A.A., Millett, C., 2015. Potential impacts of subsidised bus travel for older people. Journal of Transport \& Health 2(1), 32-34.

Mouwen, A., 2015. Drivers of customer satisfaction with public transport services. Transportation Research Part A: Policy and Practice 78, 1-20.

Newbold, K.B., Scott, D.M., Spinney, J.E.L., Kanaroglou, P., Páez, A., 2005. Travel behavior within Canada’s older population: A cohort analysis. Journal of Transport Geography 13(4), 340-351. 
O'Neill, D., 2016. Towards an understanding of the full spectrum of travel-related injuries among older people. Journal of Transport \& Health 3(1), 21-25.

Olawole, M.O., Aloba, O., 2014. Mobility characteristics of the elderly and their associated level of satisfaction with transport services in Osogbo, Southwestern Nigeria. Transport Policy 35, 105-116.

Ortúzar, J.de D., Willumsen, L.G., 1999. Modelling transport. Chichester: John Wiley \& Sons. Pai, C.W., Saleh, W., 2007. Exploring motorcyclist injury severity resulting from various crash configurations at T-junctions in the United Kingdom: An application of the ordered probit models. Traffic Injury Prevention 8(1), 62-68.

Redmond, L.S., Mokhtarian, P.L., 2001. The positive utility of the commute: Modeling ideal commute time and relative desired commute amount. Transportation 28(2), 179-205.

Ritter, A.S., Straight, A., Evans, E., 2002. Understanding Senior Transportation: Report and Analysis of a Survey of Consumers Age 50+. AARP Public Policy Institute, Washington, D.C., United States.

Rojo, M., dell'Olio, L., Gonzalo-Orden, H., Ibeas, Á., 2013. Interurban bus service quality from the users' viewpoint. Transportation Planning and Technology 36(7), 599-616.

Schmöcker, J.D., Quddus, M.A., Noland, R.B., Bell, M.G.H., 2008. Mode choice of older and disabled people: A case study of shopping trips in London. Journal of Transport Geography 16(4), 257-267.

Shiau, T.A., Huang, W.K., 2014. User perspective of age-friendly transportation: A case study of Taipei City. Transport Policy 36, 184-191.

Su, F., Bell, M.G.H., 2009. Transport for older people: Characteristics and solutions. Research in Transportation Economics 25(1), 46-55.

Su, F., Bell, M.G.H., 2012. Travel differences by gender for older people in London. Research in Transportation Economics 34(1), 35-38.

Szeto, W.Y., Yang, L., Wong, R.C.P., Li Y.C., Wong, S.C. 2017. Spatio-temporal travel characteristics of the elderly in an aging society. Travel Behaviour and Society 9, 1020.

Transport Department, Hong Kong, 2014. Travel Characteristics Survey 2011 Final Report.

Tyrinopoulos, Y., Antoniou, C., 2008. Public transit user satisfaction: Variability and policy implications. Transport Policy 15(4), 260-272.

United Nation, 2015. World Population Ageing 2015. United Nation Publication, New York, United States.

Voss, C., Sims-Gould, J., Ashe, M.C., McKay, H.A., Pugh, C., Winters, M., 2016. Public transit use and physical activity in community-dwelling older adults: Combining GPS and accelerometry to assess transportation-related physical activity. Journal of Transport \& Health 3(2), 191-199.

Wong, R.C.P., Szeto, W.Y., 2017. An alternative methodology for evaluating service quality of urban taxis. Transport Policy, under review.

Wong, R.C.P., Szeto, W.Y., Wong, S.C., Yang, H., 2014. Modelling multi-period customersearching behaviour of taxi drivers. Transportmetrica B: Transport Dynamics 2(1), 4059.

World Health Organization, 2002. Active Ageing: A Policy Framework. Madrid: World Health Organization.

Zheng, Z., Liu, Z., Liu, C., Shiwakoti, N., 2014. Understanding public response to a congestion charge: A random-effects ordered logit approach. Transportation Research Part A: Policy and Practice 70, 117-134. 